\title{
The Implications of Rainfall Variability on Cattle and Milk Production in Jakiri Sub-Division, North West Region, Cameroon
}

\author{
Emmanuel Sunjo Tata ${ }^{1}$, Sunday Shende Kometa ${ }^{1} \&$ Amawa Sani Gur ${ }^{1}$ \\ ${ }^{1}$ Department of Geography, FSMS, University of Buea, Camerron \\ Correspondence: Sunday Shende Kometa, Department of Geography, FSMS, University of Buea, P. O. Box 63, \\ Buea, Camerron. E-mail: shendek@hotmail.com
}

Received: April 9, 2012 Accepted: April 23, 2012 Online Published: September 13, 2012

doi:10.5539/jas.v4n10p237 URL: http://dx.doi.org/10.5539/jas.v4n10p237

\begin{abstract}
The rapidly increasing demand for beef and dairy products especially milk in an environment that has become super sensitive to climate vagaries as a result of climate change and variability have no doubt become a topical issue in today's man-environment relationship debate. Cattle production in Jakiri is an activity that derives its mere existence from the primary resource base of rangelands (pasture) and water availability. Intra as well as inter-annual variability and trends of rainfall thus play an important role in determining this resource base and water availability on which cattle production depends in this area. Furthermore, the quantity of milk produced significantly depends on the availability of this resource base to the cows that are used for crude milk harvesting. This study therefore sets out to examine the extent to which rainfall variability has been affecting cattle and milk production which sustains a good number of livelihoods in the area. Being located within the Montane Guinea savannah ecological zone of Cameroon, the study makes use of rainfall data for a period of 33 years and commercial milk production figures since its introduction in Jakiri in 1998. These recorded data were complemented with field surveys, focus group discussions with the graziers and the milk production farmers, field interviews with veterinary experts and secondary data. Although rainfall and milk production relationships on annual and dry season bases do not seem statistically significant, they however do so, on wet season basis. The increasing variability of rainfall especially during the dry season significantly necessitate the transhumant operation into the neighbouring river valleys and flood plains. Given this intricate relationship between rainfall and cattle production as well as other threats to the full functioning of rangelands, the study proposes recommendations that if implemented, can boost cattle and milk production that sustains the lives of people.
\end{abstract}

Keywords: rainfall variability and trends, cattle and milk production, and Jakiri Sub-Division

\section{Introduction}

Cattle and milk production in Jakiri Sub-Division is an activity that employs both the migrated Fulanis and the indigenes of the area. Besides providing employment, the products from this activity are in high demand from the increasing populations in Jakiri in particular, and the North West Region in general (Ndenecho \& Balgah, 2007). The production of cattle in this area lends credence to the interaction of average rainfall, temperature, elevation and latitude to provide rangeland herbaceous species, shrubs and/or open stands of trees (Strahler \& Strahler, 2005; Krebs, 1792). In much the same way as Watson et al. (1996) pointed out, while the contribution of grazing systems to the world's meat and dairy supplies is limited, these systems have the most direct interface between livestock and land, water and biodiversity which covers a sizeable proportion of the usable surface area of Jakiri Sub-Division. This vegetation supports cattle production in particular and pastoralism in general. This paper therefore aims at examining the variability in rainfall and the ecological transformation of rangeland on cattle production in Jakiri. This paper also establishes the extent of rainfall variability and trends with respect to seasonality and annual patterns as well as the ecological situation in Jakiri and its changing patterns over time.

\section{The Problem}

The profound decline in the production of beef, dairy products as well as cattle numbers has become a cause for concern as to what must have orchestrated them. Perhaps whether a coincidence or not, the decline appears to have been in line not only with the degradation of the ecological status of the rangeland but equally with the increasing deterioration of the climatic conditions especially. These worsening climatic conditions are reflected through increasing variability, reducing amounts of rainfall over time and the increasing aridity of the dry season that is 
associated with the enhanced decline in drier season rainfall. The results of these are two-fold; they have not only threatened the standard of living of mankind in terms of the reduced quality of diet, but, also employment given that cattle production generally constitutes a major aspect of agriculture which is the backbone of the economy of Cameroon in general and Jakiri in particular. Furthermore, the dominantly rangeland ecology of this area has been greatly transformed. This is an area closer to the Sudano-Sahelian belt that has been witnessing desertification. Yet, this area has, through time, witnessed increased growth in settlement, deforestation and especially unsustainable agricultural practices such as over-grazing, slash-and-burn and shifting cultivation. These activities have greatly enhanced the transformation of the ecology of the area thus, undermining cattle production efforts. Furthermore, the introduction of milk production in the area since the last quarter of the 1990s has been greeted as a new innovative idea since it has helped in keeping the Fulani woman busy. However, the continuous variations in rainfall in the area has been a threat to the sustenance of milk production especially during dry spells when pasture and water availability

\section{Materials and Methods}

Jakiri Sub-Division is located in the North West Region of Cameroon (Map 1). This area lies on latitude $6^{\circ}$ north of the Equator and longitude $10^{\circ}$ East of the Greenwich Meridian. It has a surface area of about $675 \mathrm{~km}^{2}$, with an altitude of about 5500 feet above sea level (Helvetas-Cameroon, 2006, in Tata, 2008). The area has a climate that could be described as a transitional montane and the Sudan type, with alternating wet season (March to October) and dry season (November to February). This climate has thus favoured greatly the savannah vegetation that provides rangelands with suitable species of herbs, shrubs and dotted stands of trees.

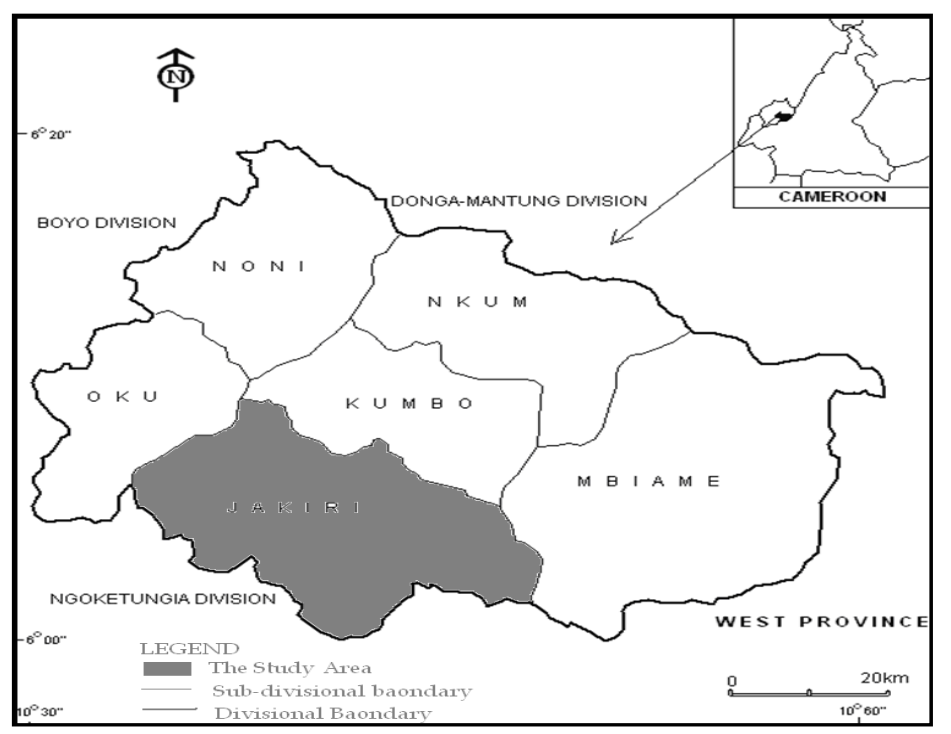

Map 1. Location of Jakiri Sub-Division in the North West Region, Cameroon

The study made an extensive analysis of intra and inter-annual rainfall variability from rainfall data covering a period of about 33 years. Running averages in blocks of 7 on both annual and seasonal bases as well as their dependable rainfall were computed to know the trends in the rainfall patterns in Jakiri over the same period. The rainfall data was collected from the Divisional Office in Jakiri, while milk production figures were compiled from the registers and final reports of Community Dairy Farming Organisations in the area.

The link between rainfall variability and milk production on annual as well as seasonal bases was computed using the Product Moment Correlation Coefficient and the accompanying student t-test with their respective degrees of freedoms to examine if such a relationship was scientifically significant or not. Furthermore, field observations were done in 2008, 2009, and 2010 on the spatio-temporal growth of human activities such farmlands, settlements, and the planting of eucalyptus plant species which is considered to be 'an environmental terrorists' on rangelands. These observations helped in assessing the extent of the transformation of the dominantly rangeland ecology in Jakiri Sub-Division. Interviews and disease diagnosis were also done with the Veterinarian in order to acquire information on the deseases affecting cattle and the seasons in which they are most prevalent. The relationship between rainfall variability and milk production (on annual and seasonal bases) was computed using the Person's Product Moment Correlation Coefficient. The probability value was 0.05 level of significance. 


\section{Rainfall Variability and Trends}

From the data collected, different periods of grazing and the availability of endemic cattle forage in particular areas have shown that rainfall is not evenly distributed in the area. Perhaps this could be linked to the fact that a greater proportion of the Sub-Division (such as Vekovi, Ntunir and Tashem) is located on a higher altitude on the South Western part while the rest is made up of lowland areas especially those on valley sites and on the upper edge of the Ndop plain such as Ber and Wasi located. Moreover, some areas such as Vekovi, Shuukov and Yer possessing much of forest vegetation, exist alongside the dominantly Savannah vegetation areas in Tan, Ntunir and Wainamah. In line with Money (1956), these factors act significantly in determining the convective activities of the South West Monsoon winds that help in bringing moisture from the Atlantic Ocean and thus account for the spatial rainfall variations.

The calculated Co-efficient of Variance (C.V.), expressed as a Percentage, indicates the dependability of rainfall for cattle production in Jakiri Sub-Division. In this regard, the threshold levels of C.V. for the interpretation are: yearly rainfall: $<25 \%$, seasonal rainfall: $<50 \%$ (Storch \& Zwiers, 1999). Jakiri, with a C.V. of $10.05 \%$ (for the 33 year-data) within the annual threshold limit of $<25 \%$ indicated that the occurrence of mean annual rainfall $(2101.9 \mathrm{~mm})$ is highly dependable and variation is minimal. This average rainfall amount is needed for the growth of cattle forage and so favours cattle production. Yearly deviation of rainfall using the 7-year running mean reveals that rainfall amounts over the 33 years period under study have decreased. The absolute sum of the deviations during the 7-year block periods has shown a sharp and continuous increase, depicting an increase in variability, as shown in Figures $1 \& 2$.

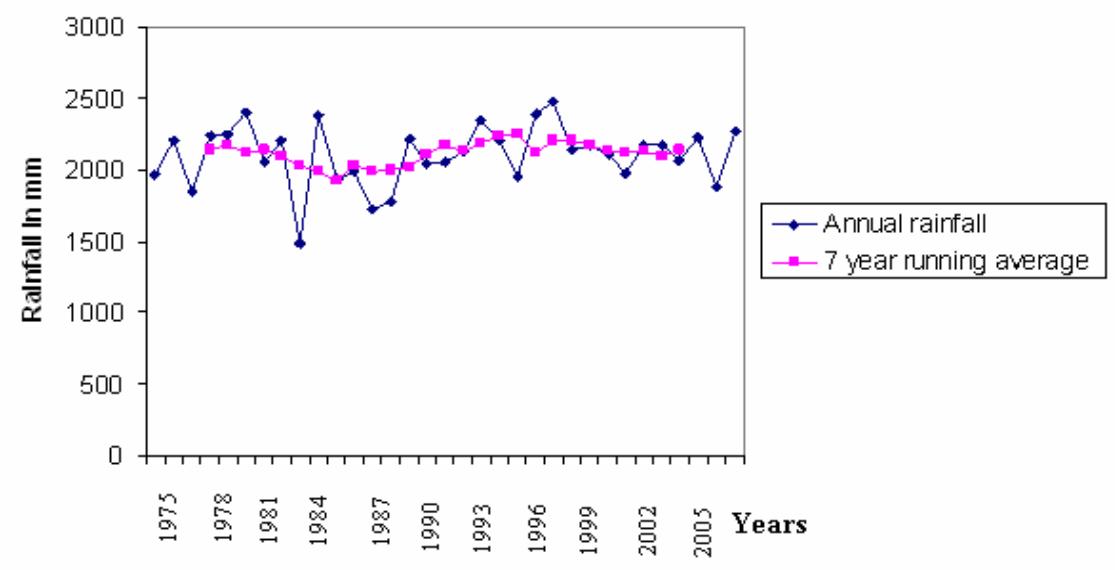

Figure 1. Annual Rainfall and Trends in blocks of 7 (Moving Averages)

From 1975-2007 (Source: Adapted from Appendix 1)

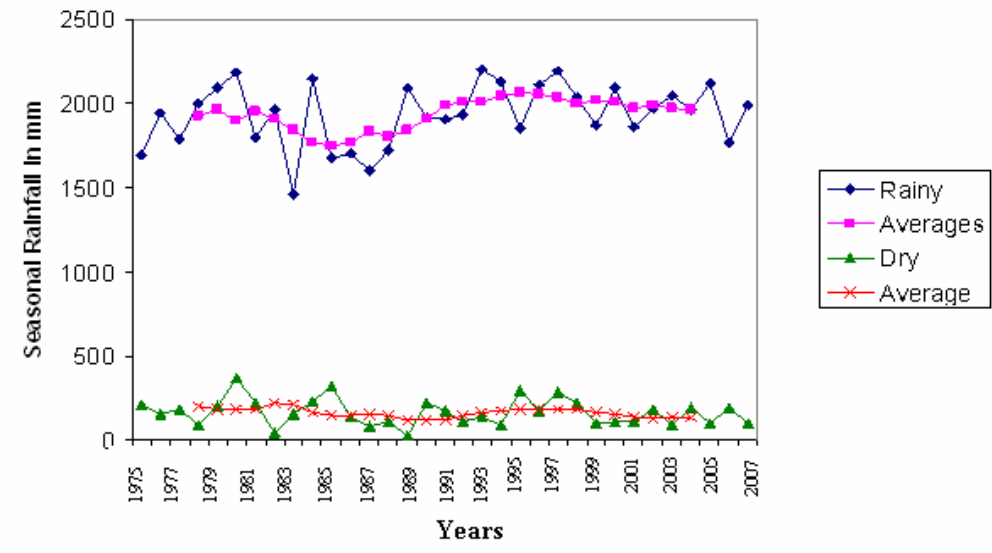

Figure 2. Seasonal Rainfall and trends in blocks of 7 from 1975-2007

(Source: Adapted from Appendix 1) 
On seasonal basis, the variability and the respective 7 -year running means depict that cattle production can depend with some greater certainty on rainfall during the wet (rainy) season. The calculated seasonal C.V of $9.8 \%$ falls within the seasonal threshold range of $<50 \%$. Though the dry season C.V of $47.8 \%$ falls within the threshold limit of $<50 \%$, this dependability is however questionable owing to the high value, which is almost at the threshold level of $50 \%$. This explains why during the dry season, herders and their herds undertake the transhumance operation in to valleys and the Ndop Plain and only return during the wet season. Just like the annual trends, seasonal trends of rainfall over the 33 years considered have been seen to be decreasing especially during the last 7 years. The season wise deviation of rainfall has also been studied using the 7- year running mean. The last 7 years depict a greater decrease of rainfall during the wet season, which shows much variability. However drastic reduction of rainfall has been during the dry season with greater variability. In Table 1, Jakiri Sub-Division has a total grazing land classified according to ardorate (a rangeland side that is under the care of an Ardo - the Muslim leader in the rangeland) of about 5350ha with 12226 cattle grazing on them, and controlled by 342 herders.

Table 1. The relationship between rangeland and cattle number

\begin{tabular}{ccc}
\hline No of graziers & Grazing Area (x) & Number of cattle (y) \\
\hline 40 & 800 & 2000 \\
22 & 350 & 800 \\
30 & 250 & 500 \\
15 & 200 & 500 \\
25 & 300 & 1000 \\
100 & 1500 & 4000 \\
70 & 950 & 1500 \\
40 & 1000 & 1926 \\
\hline Total: 343 & $\mathbf{5 3 5 0}$ & $\mathbf{1 2 2 2 6}$ \\
\hline
\end{tabular}

Source: Sub-Delegation of MINEPIA 2008 Annual Report.

\section{Rangeland Ecological Situation}

Jakiri has a grazing area of about $5350 \mathrm{ha}$ of the $675 \mathrm{~km}^{2}$ total surface area (MINEPIA, 2007 in Tata, 2008). The changing seasons and sustained climatic variability have significantly influenced rangeland transformations on which livestock especially cattle production depend. The pendulum-like transformation of the ecology from luxuriant growth in biodiversity and water availability during the wet season, to near loss of biodiversity and the drying up of most water points exacerbated during prolonged periods of drought conditions in the dry season acts as a yard stick of assessing the positive and negative implications of such transformation on cattle production (Chapman \& Reiss, 1999; Ndenecho, 2005). Such transformation is seen to be as a result of climatic factors, fires, land use and management and the planting of the exotic eucalyptus tree species. This last factor has been seen largely as an anthropogenic-induced cause of such transformation with great severity. The transformation of the ecology of Jakiri from the analysis has to an extent been the interaction of rangelands and the number of cattle on them in Table 1, which greatly reflects the carrying capacity of the total grazing land. This has been statistically proven since, with the degree of freedom of 6 , the table $t$-value at $5 \%$ level of significance is 2.45 . Since the table value (2.45) is less than the calculated $\mathrm{t}$-value (2.95), there is therefore a high correlation between the transformation of the ecology and cattle production in Jakiri Sub-Division. One can therefore say with of certainty, that the positive correlation result of 0.77 must not have occurred by chance.

Furthermore, the seasonal climatic changes in rangelands influence the pattern of diseases that affect cattle (Ayouade, 1993). Their prevalence is significantly attributed to the interaction between the climatic parameters of moisture, temperature and relative humidity. The upland rangelands though abundantly blessed with fodder during the wet season, are marked by the prevalence of wet season diseases. In much the same way, though the dry season transhumance areas provide the scarce fodder during this season, the prevailing ecological conditions also permit the breeding of a number of disease vectors and parasites that affect cattle production (Table 2). These diseases do not only result in morbidity and mortality, but the morbid state of the cattle equally affects milk production, as the quality and quantity drop due to emaciation. 
Table 2. Common diseases affecting cattle

\begin{tabular}{ll}
\hline \multicolumn{1}{c}{ Wet Season } & \multicolumn{1}{c}{ Dry Season } \\
\hline - Endo-parasitic effects caused by & - Rinderpest \\
round worm and tape worm & - Trypanosomiasis in low land and \\
- Ecto-parasitic effects caused by & forest areas during the transhumant \\
heavy thick infestation and ring & operation e.g. Ber and Wasi at the edge \\
worm & of Ndop plain \\
- Food and mouth disease & - Tuberculosis \\
- Mastitis & - Contagious Bovine-pleuropneumonia \\
- babesiosis & and Haemorrhagic septicaemia \\
- Black quarter- & \\
\hline
\end{tabular}

Source: Interview with the Veterinarian and from the 2009 Reported Diagnosed Cases in the Sub Delegation of Livestock and Fisheries.

\section{Rainfall and Milk Production}

Rainfall variability and trends were also correlated with milk production on seasonal bases (Table 3 ). Though it has been noted that such links are incompatible, it is important to point out that it is as a result of the subsistence level of dairy activities in the area. The number of cattle used for calving and the quantity of calved milk is too small to be linked to the rainfall with an average of $2101.9 \mathrm{~mm}$.

Table 3. Seasonal rainfall and milk production figures from 1998 to 2007

\begin{tabular}{ccccc}
\hline Year & \multicolumn{2}{c}{ Rainfall in mm } & \multicolumn{2}{c}{ Milk production in litters } \\
\cline { 2 - 5 } & Wet Season & Dry Season & Wet Season & Dry Season \\
\hline 1998 & 2034.5 & 223.3 & 1635.1 & 1290.5 \\
1999 & 1870.1 & 102.7 & 1094 & 492.5 \\
2000 & 2090.5 & 113.1 & 2130 & 711 \\
2001 & 1857.4 & 115 & 2292 & 1828 \\
2002 & 1976.7 & 180.7 & 1864 & 2338.1 \\
2003 & 2046.0 & 90.8 & 1698 & 2195 \\
2004 & 1960.8 & 191.3 & 3359.7 & 3207.5 \\
2005 & 2123.8 & 103.7 & 4480 & 1742 \\
2006 & 1723.8 & 193.4 & 4275.3 & 2827 \\
2007 & 1992.1 & 98.7 & 2881 & 2040 \\
\hline Total & 19675.7 & 1412.7 & 25709.1 & 17716.6 \\
\hline
\end{tabular}

Source: Sub-Divisional Office Meteorological Station (Rainfall Amounts) and Community Dairy Organisation Reports (Milk Figures), 2008

With a degree of freedom of 8 at 0.05 level of significance, we can conclude that there is no correlation between rainfall and milk production on wet season basis. The production and processing of milk in the area in 1996 started timidly. Milk production amounts however increase from 1999 up to 2005 although the wet season quantity dropped again in 2006 and 2007. Similarly, with a degree of freedom of 8 at the $5 \%$ level of significance, there is no correlation between dry season conditions and dry season milk production, since the table t value of 2.31 is greater than the calculated $t$ value of 1.43. It can thus be concluded that the positive correlation coefficient of 0.45 must have occurred by chance, and as such, not statistically significant.

\section{Conclusion}

This study has assessed the relationship that exist between rainfall variability on one hand and cattle and milk production on the other hand. The analysis further show that rainfall affects the rangeland conditions of the area and with concomitant effects on cattle grazing and milk production. Therefore, the constant climatic fluctuations and the unsustainable activities of humankind in this highland area are some of the major problems that affect the 
full functioning of the rangeland ecosystem with respect to sustaining cattle production. Among the uunpleasnt human activities that have significantly transformed the rangeland ecology are the extension of crop production and settlements into the rangelands, the frequency of bush fires, and the planting of the exotic eucalyptus plant species which brings more aridity in rangelands. It is, therefore, based on the importance of this activity that the recommendations which follow have been made, which, if implemented, could contribute significantly in improving cattle production in the midst of a constantly variable climate in the area like elsewhere in the world.

\section{Recommendations}

To ensure cattle production with respect to milk production, the encroachment of farmlands and settlements into rangelands, such as the planting of Eucalyptus, deforestation through burning of rangelands by the local population should be discouraged since together with the climatic stressor, they help in negatively transforming the ecology of the area. This would help in not only restoring the biodiversity of the area and increasing stream discharges (Amawa, 2001), but will enhance greater convective activities through minimising the albedo aspect and enhancing the absorption of solar radiation (and thus increasing the rainfall amounts).

There should be a revitalisation of the National School of Livestock and Veterinary Sciences in Jakiri, whose activities has, for quite some time now, declined and even stopped since 2008. It should be raised even to International standard. This can be done by recruiting professionals and technical trainers and increasing the existing structures to at least fair standards. The training of such experts and technicians in the cattle rearing fields, together with the existing National Corporation for Animal Production (SODEPA), co-working with herders, can help intensify cattle and milk production by using more capital-intensive means to help raise production. They will also help a lot in understanding and mitigating the negative effects of pests and diseases that affect cattle.

Though rainfall data when analyzed do not show much variation when compared to cattle production (milk production in this case), meteorological stations should be equipped with a good number of weather instruments to record not only rainfall as it is the case in the area, but also other weather elements sich as temperature, humidity, and windspeed among others which are other climatic components that affect livestock and milk production in the area by the stake holders concerned. This will help provide climatic data which when analysed could be useful in the monitoring and management of rangelands to ensure the sustainability of free range grazing in the sub-division. Besides, the data could be of assistance to crop farmers, especially in predicting the planting period with some degree of certainty. This is important as the results from the field show that ecological transformation has a negative effect on cattle productionThough a lot has been done in this area by the Heifer International Organisation (a Non-Governmental Organisation) in the commercialisation of milk, more still needs to be done by the Government of Cameroon and the local council, by the way of the provision of storage facilities for milk which is a vital ingredient in the diets of the people.

\section{References}

Amawa, S. (2001). Variations in Spring Discharge on the Mbum Plateau (N.W. Province of Cameroon), In. C. Lambi (Ed) Readings in Geography, Unique Printers Bamenda.

Ayoade, J. O. (1993). Introduction to Climatology for the Tropics: $3^{\text {rd }}$ Edition, Spectrum Books limited, Ibadan, Nigeria.

Brown, R. J., Blank, R. R., McPherson, R. G., \& Tate, W. K. (2010). Rangelands and Global Change: An Issue Paper Created by the Society for Range Management, www.rangeland.org (Accessed on 21/01/2011)

Chapman, J. L., \& Reiss, M. J. (1999). Ecology: Principles and Applications, Second Edition, Cambridge University Press Syndicate, Britain.

Krebs, G. J. (1972). Ecology, $1^{\text {st }}$ Edition, Harper and Row Publishers Inc, New York, U.S.A.

Lambi, C. M. (2001). Revisiting the Trilogy: Man, Environment and Resources: In Lambi, C.M. (Ed., 2001). Environmental Issues: Problems and Prospects, Unique Printers, Bamenda, pp. 105-117.

Money, D. C. (1993). Climate, Soils and Vegetation, $3^{\text {rd }}$ Edition, University Tutorial Press LTD, Great Britain.

Ndenecho, E., \& Balgah, S. (2007). The Population - Resources Scarcity and Conflict Trinity; Analysis of North-West Cameroon, $1^{\text {st }}$ Edition, Unique Printers, Bamenda, Cameroon.

Ndenecho, E. N. (2005). Biological Resource Exploitation in Cameroon, $1^{\text {st }}$ Edition, unique Printers, Bamenda, Cameroon.

Storch, H. V., \& Zwiers, F. W. (1999). Statistical Analysis in Climate Research, $1^{\text {st }}$ Edition, University Press Cambridge, United Kingdom. 
Strahler, A., \& Strahler, A. (2005). Physical Geography: Science and Systems of the Human Environment, $3^{\text {rd }}$ Edition, Von Hoffman Press, Inc, U. S. A.

Tata, E. S. (2008). Rainfall Variability, Ecological Transformation and Implications for Cattle Production in Jakiri Sub-Division, North west Region of Cameroon, Unpublished B.Sc Long Essay, Department of Geography, University of Buea.

Thomas, D., \& Barton, D. (1995). Livestock and the Environment Finding a Balance Interaction between Livestock Production Systems and the Environment Impact Domain: Crop-Livestock Interactions, Coordination by Food and Agriculture Organization of the United Nations, United States (U.S. Agency for International Development) and the World Bank.

Watson, R. T., Zinyowera, M. C., Moss, R. H., \& Dokken, D. S. (1996). Climate Change 1995: Impacts, Adaptations and Mitigations of Climate Change: Scientific Technical Analyes, $1^{\text {st }}$ Edition, Press Syndicate of the University of Cambridge, New York.

Appendix 1. Annual Seasonal Rainfall Variability for in Jakiri from 1975-2007

\begin{tabular}{|l|l|l|l|}
\hline Year & Annual Rainfall in $\mathrm{mm}$ & \multicolumn{3}{|l|}{ Seasonal Rainfall in $\mathrm{mm}$} \\
\cline { 3 - 4 } & & Rainy & Dry \\
\hline 1975 & 1967.14 & 1694.04 & 214.2 \\
\hline 1976 & 2198.5 & 1943.2 & 161.9 \\
\hline 1977 & 1847.5 & 1787.2 & 182.7 \\
\hline 1978 & 2234.6 & 2004.6 & 92.8 \\
\hline 1979 & 2242.7 & 2088.5 & 200.7 \\
\hline 1980 & 2397.2 & 2189.2 & 370.4 \\
\hline 1981 & 2055.3 & 1794.2 & 220.7 \\
\hline 1982 & 2199.3 & 1963.9 & 45.7 \\
\hline 1983 & 1486.5 & 1459.4 & 159.8 \\
\hline 1984 & 2374.4 & 2152.2 & 231.1 \\
\hline 1985 & 1928.0 & 1680.3 & 323.8 \\
\hline 1986 & 1985.3 & 1703.2 & 135.9 \\
\hline 1987 & 1725.0 & 1598.0 & 83.4 \\
\hline 1988 & 1777.9 & 1718.0 & 106.6 \\
\hline 1989 & 2217.5 & 2094.9 & 31.02 \\
\hline 1990 & 2036.9 & 1916.8 & 219.6 \\
\hline 1991 & 2048.8 & 1909.4 & 172.1 \\
\hline 1992 & 2125.2 & 1939.3 & 110.0 \\
\hline 1993 & 2340.7 & 2203.2 & 135.4 \\
\hline 1994 & 2208.1 & 2129.2 & 92.5 \\
\hline 1995 & 1950.7 & 1855.5 & 294.9 \\
\hline 1996 & 2385.4 & 2109.8 & 171.7 \\
\hline 1997 & 2472.1 & 2198.5 & 287.9 \\
\hline 1998 & 2143.1 & 2034.5 & 223.3 \\
\hline 1999 & 2166.6 & 1870.1 & 102.7 \\
\hline 2000 & 2100.9 & 2090.5 & 113.1 \\
\hline 2001 & 1971.7 & 1857.4 & 115.0 \\
\hline 2002 & 2172.2 & 1976.7 & 180.7 \\
\hline 2003 & 2173.3 & 2046.0 & 90.8 \\
\hline 2004 & 2057.1 & 1960.8 & 191.3 \\
\hline 2005 & 2223.4 & 2123.8 & 103.7 \\
\hline 2006 & 1881.6 & 1723.8 & 193.4 \\
\hline 2007 & 2268.6 & 1992.1 & 98.7 \\
\hline & & \\
\hline & & & \\
\hline
\end{tabular}

Source: Sub-Divisional Office Meteorological Station, 2008. 